\title{
End-of-life care for advanced dementia patients in residential care home-a Hong Kong perspective
}

\author{
James K. H. Luk, Felix H. W. Chan \\ Department of Medicine and Geriatrics, Fung Yiu King Hospital, Hong Kong, China \\ Correspondence to: Dr. James K. H. Luk, MBBS, MSC, FRCP, FHKCP, FHKAM. Consultant, Department of Medicine and Geriatrics, Fung Yiu King \\ Hospital, 9 Sandy Bay Road, Pokfulam, Hong Kong, China. Email: lukkh@ha.org.hk.
}

\begin{abstract}
Dementia will become more common as the population ages. Advanced dementia should be considered as a terminal illnesses and end-of-life (EOL) care is very much needed for this disease group. Currently, the EOL services provided to this vulnerable group in Hong Kong, especially those living in residential care homes, is limited. The usual practice of residential care homes is to send older residents with advanced dementia to acute hospitals when they are sick, irrespective of their wish, premorbid status, diagnoses and prognosis. This may not accord with what the patients perceive to be a "good death". There are many barriers for older people to die in place, both at home and at the residential care home. In the community, to enhance EOL care to residential care home for the elderly (RCHE) residents, pilot EOL program had been carried out by some Community Geriatric Assessment Teams. Since 2015, the Hospital Authority funded program "Enhance Community Geriatric Assessment Team Support to End-of-life Patients in Residential Care Homes for the Elderly" has been started. In the program, advance care planning (ACP), Do Not Attempt Cardiopulmonary Resuscitation (DNACPR) (non-hospitalized) order will be established and the program will be expected to cover all clusters in Hong Kong by 2018/2019. In hospital setting, EOL clinical plan and EOL ward in geriatric step-down hospitals may be able to improve the quality of death of older patients. In Sep 2015, the Hospital Authority Guidelines on Life-Sustaining Treatment in the Terminally Ill was updated. Amongst other key EOL issues, careful (comfort) hand feeding was mentioned in the guideline. Other new developments include the possible establishment of enduring power of attorney for health care decision and enhancement of careful hand feeding amongst advanced dementia patients in RCHEs.
\end{abstract}

Keywords: End-of-life (EOL); advanced dementia; residential care home for the elderly (RCHE)

Submitted Apr 14, 2017. Accepted for publication Aug 08, 2017.

doi: 10.21037/apm.2017.08.13

View this article at: http://dx.doi.org/10.21037/apm.2017.08.13

\section{Introduction}

Hong Kong is facing rapid population aging (1). The demographic changes create an imminent need for endof-life (EOL) care among the older people with advanced dementia. Dementia will become more common as the population ages. The dementia disease trajectory at the later stage are often complicated by eating problems with poor appetite and swallowing difficulty, malnutrition, weight loss, aspiration pneumonia (AP) and death (2). Patients with advanced dementia have high mortality but this is not usually recognised (3). One local study on older residents with advanced cognitive impairment living in residential care home for the elderly (RCHE) showed a 1-year mortality rate of $34 \%$ (4). As the EOL approaches, the pattern in which patients with advanced dementia experience distressing symptoms is comparable to patients dying of other terminal conditions (5). Hence, it is advocated that advanced dementia should be considered as a terminal illness and EOL care is very much needed for this disease group (6).

\section{"Good death"}

The concept of a "good death" has been described as 
including to be able to know when death is coming, retain control of what happens, having dignity and privacy, pain and symptom control, choice and control where death occurs (at home or elsewhere), access to information and expertise, access to spiritual or emotional support, access to hospice care in any location, control over who is present, able to issue advance directives, have time to say goodbye and leave when it is time to go instead of prolonging life pointlessly (7). Other elements are clear decision making, preparation for death (life review, resolving conflicts, spending time with the family, saying good bye, and promoting the well-being of family and caregivers) and affirmation of the whole person (reception of empathic care from caregivers, sharing memoires, promoting privacy and encouraging physical touch) (8).

In Hong Kong, if not all, most patients with advanced dementia die in hospitals. The acute medical and surgical wards are common places where these older people died (9). However, these wards are not equipped with training or facilities to allow older people to die with dignity. There is an inappropriate use of hospital services, with unnecessary transportation of ill elderly who will die in an unfamiliar environment with restricted visiting hours, and inability of acute ward staff to bestow time to offer a "good death" experience to patients or support with family bereavement (10).

\section{Dying in place for advanced dementia}

As mentioned above, option of "dying in place" is one of the good death elements (11). Dying in place means dying in a familiar environment and in the company of family members. It usually means dying at home or in RCHE (12).

There are still numerous hitches for dying in place in Hong Kong $(13,14)$. These barriers include social taboo, lack of death education, and the lack of systematic researches of the preferences and attitudes of our elderly population. More precisely, as to dying at home, one barrier is the fear of depreciation of property value if somebody died at home and the lack of necessary medical support (to care for the dying person at home). In the case of RCHEs, staff have generally not been trained in how to manage dying patients, and as a result, they prefer residents do not die while under their care. Many RCHEs are overcrowded and there is no extra room in which a resident may pass away peacefully with privacy. The geriatric and palliative care support available to RCHEs are also inadequate. The non-existence of a system of family practice, where doctors have established a considerable period of professional care and knowledge of their patients and would visit patients at home or RCHE, including taking care of their EOL stage and certifying death, is also another major barrier.

\section{Dying at home}

In Hong Kong, there is no need to report to the coroners if a person dies at home. However, a registered practitioner must fill out a Medical Certificate of the Cause of Death (Form 18) of the Births and Deaths Registration Ordinance (chapter 174). The Form is available in offices of the Registrar of Births and Deaths (15). In order to do so, she/he must have attended the patient within 14 days immediately prior to the patient's death. With Form 18, the deceased's family is under a duty to register a death within 24 hours at one of the Death Register Offices. After death registration, a Certificate of Registration of Death (Form 12) will be issued. According to section 16 of the Births and Deaths Registration Ordinance, no person shall remove a dead body, unless they have obtained either Form 12, or in urgent cases, a permit from the nearest police station (16).

Although the law does not require death at home be reported to the coroner, the major obstacles to dying at home are many-folded: the fear that death at home may affect property value, the lack of adequate care available at home, the lack of doctors who are willing to home visit dying patients and provide Form 18, and finally the lack of sufficient ancillary medical support for the care of dying patients at home.

\section{Dying in residential care homes in Hong Kong}

In many Western and in some Asian countries, a combined approach of residential setting and a palliative care unit are used. As RCHEs are for dependent elderly people, it is common for them to die there and so EOL care is an integral part of their service. However, in Hong Kong, one of the major barriers is legal, as the Coroner Ordinance (section 4, Coroner Ordinance, CAP 504) demands that all deaths in RCHE (except nursing homes which provides care for older people with severe impairment level, have a higher staff-to-resident ratio and are better equipped) be reported to the coroner (17). The aim of this compulsory reporting requirement is to allow the coroner to investigate deaths with unknown or suspicious causes. After reporting to the coroner, a police report will be made to the coroner. Police will then inform the next-of-kin of the place and time for an interview with a forensic pathologist. During 
the investigation, the death body has to be placed in a public mortuary. To avoid the above hassles of coroner and police involvement, RCHE staff will be reluctant to let the elderly resident to die in their premises. When they see a patient is deteriorating, they will quickly call the ambulance and send them to the emergency.

In Hong Kong, around $8.5 \%$ of those aged 65 and over are living in RCHEs. The residents are characterised by a high prevalence of multiple comorbidities, especially advanced dementia (18). One study of private care homes showed that $18 \%$ of the residents there had an abbreviated mental test (AMT) score $=0$ (19). A study in RCHEs in 2007 revealed that $28.8 \%$ of the residents wished to pass away in RCHEs instead of in hospital (20). Another local study involving RCHE residents and EOL care preferences showed that $35 \%$ of older residents would prefer to die in their RCHEs (21). A pioneer program in Heaven of Hope Nursing Home has achieved favourable results with nearly $30 \%$ of all deaths occur in the nursing home (22).

A new model of EOL care has been carried out in New Territory East in Hong Kong aiming at promoting quality EOL care for RCHE residents, through the establishment of ACP and introduction of a new care pathway (23). This pathway bypassed the emergency room (ER) and acute medical wards by facilitating direct clinical admission to an extended-care facility. A study on this program shows that nearly $40 \%$ of EOL patients could be managed entirely in an extended-care setting without compromising the quality of care and survival.

In Hong Kong West, the Hong Kong West Community Geriatric Assessment Team (HKW CGAT) piloted the EOL program for RCHE in cooperation with two Care and Attention Homes in September 2009 (24). The objectives of the program were to provide palliative care for older residents in RCHEs who had irreversible chronic medical diseases, ensured the elderly could enjoy a dignified and comfortable period in a familiar environment before they died, reduced acute hospital admission and to serve as a model of care in Hong Kong. The project aimed at attending residents with irreversible chronic medical illnesses. These included residents with advanced dementia, cancer, organ failure (such as endstage heart failure or renal failure) and degenerative neurological diseases. The Gold Standards Framework for the Three Illness Trajectories was used to identify suitable candidates to join the EOL program (25). These included the cancer trajectory, organ/system failure trajectory and the dementia/frailty trajectory. In the program, there were weekly EOL clinics and family conferences. ACP and DNACPR (non-hospitalized) would be established. If patients were mentally sound, advance directive would also be created if the older residents wish to. The patients/ family members could select one of the two pathways, namely the hospital pathway and Accident and Emergency Department (AED) pathway. In the hospital pathway, elderly would be clinically admitted to a geriatric stepdown hospital (instead of acute hospital) which was suitable for EOL care via an expedite pathway. In the AED pathway, elderly would stay in RCHE as long as possible with support from the RCHE staff and EOL team of HKW CGAT. At the last moment (patients become unconscious, breathing becomes shallow and/or blood pressure starts to drop), they would be transferred to AED by ambulance. Resuscitation would still be carried out by the ambulance men as the Fire Services Ordinance in Hong Kong stipulates that resuscitation has to be carried out to their clients. When the patients reach AED, resuscitation would not be offered. Instead, a quiet environment would be offered to the elderly, allowing them to pass away peacefully in the AED.

An audit of the program was performed to look at the RCHE residents who had joined the piloted EOL program for RCHE and died in AED from Sep 2009 to Aug 2014 (26). Twenty-two patients joined the program with AED pathway in the audit period. According to the Gold Standards Framework - the Three Illness Trajectories, $69 \%$ of them were in the dementia/frailty trajectory, $22 \%$ in the organ failure trajectory while $9 \%$ in the cancer trajectory. Nine patients (41\%) finally died in AED. In the last 4 weeks before death, frequent ad-hoc doctor and nurse consultations per person were needed. When they arrived at AED, all were not resuscitated according to the DNACPR (non-hospitalized) order and were allocated a single room for the family members to say goodbye. In the last 180 days before death, they had an average (per person) of $2.67 \mathrm{AED}$ attendances (including death episodes in AED), 1.67 medical admissions and 16 medical bed-days. These figures were lower than those reported by the Hospital Authority in 2012 (AED attendances, 2.98; medical admissions, 2.56; medical bed-days, 26) for local RCHE residents during last 180 days of life. The conclusion was that AED pathway was logistically feasible and could serve as a new model of 
care in some local better staffed and equipped RCHEs to foster dignified death.

\section{ACP and new development of end-of-life care in residential care homes in Hong Kong}

In Oct 2015, a program to "Enhance CGAT Support to EOL Patients in Residential Care Homes for the Elderly" was implemented by Hospital Authority in Hong Kong. It was first commenced in four clusters, namely Hong Kong West, Hong Kong East, New Territories West and East in 2015. In the program, the usual CGAT service is enhanced, with link nurse to as case managers for elderly in RCHE, including those with advanced dementia, approaching EOL stage. CGAT also collaborated with palliative specialists to develop and carry out this program. Palliative specialists provide training to RCHE and CGAT staff, hold regular case conferences with HKW CGAT, and assists in complex case management. To avoid duplication of service provision, RCHE patients who have been seen by palliative team are not recruited into the CGAT EOL program. In the program, ACP would be discussed and DNACPR (non-hospitalized) order would be made (if agreed by patient or family members). Advance directive may also be signed if the patient is mentally sound. According to the plan of Hospital Authority, the "Enhance CGAT Support to EOL Patients in Residential Care Homes for the Elderly" service will expand to all clusters in Hong Kong by 2018/2019.

\section{End-of-life programs in geriatric hospitals}

As many older patients may pass away in wards, there is a need to enhance EOL services at the inpatient setting. In Hong Kong West, TWGHs Fung Yiu King hospital (FYKH) has established the End of Life Clinical Plan for inpatient (EOL CPi) since 2012. At the time of writing, the clinical plan has been used in nearly 400 patients. A study on the EOL CPi shows that a tailor-made EOL clinical plan could be useful to guide clinical team in fostering dignified death among dying older patients in a geriatric step-down hospital (27). Patients and relatives are also satisfied with the program as a whole. Recently an EOL ward with eight beds has been in place in FYKH. A preliminary study of 149 patients who died shows that EOL ward can foster dignified death by providing a peaceful environment so that family members are able to stay with the patients as long as possible before they pass away.

\section{Careful hand feeding (CHF) for advanced dementia}

Feeding problems are common in older people with advanced dementia. When eating difficulties arise, unless there is a valid advance directive refusing enteral feeding, tube feeding is often started. Tube feeding itself has many pitfalls and complications. To date, no benefits in terms of survival, nutrition and prevention of aspiration have been demonstrated. The use of feeding tube leads to patient discomfort, increased use of restraints and greater likelihood of pressure sore development $(28,29)$. Studies show that RCHE residents with feeding tubes are frequently transferred to emergency to take care of tube complications such as blockage and dislodgement (30). So far, studies have not shown survival benefits in older people with tube feeding (31). In the 2014 positional statement of feeding tubes in advanced dementia published by the American Geriatrics Society, feeding tubes are not recommended (32). It emphasizes that CHF should be offered as it is at least as good as tube feeding for the outcomes of death, AP, functional status, and comfort (33). Similar recommendations are made by the Australian and New Zealand Society for Geriatric Medicine (34). In Sep 2015, the Hospital Authority Guidelines on Life-Sustaining Treatment in the Terminally Ill was updated. Amongst other key EOL issues, it provides a clear and locally relevant picture of CHF from the ethical perspective $(35,36)$. In some geriatric step-down hospitals, CHF is already incorporated as one of the management strategies for EOL patients. Notwithstanding, there are many practical issues if tube feeding is not used in older patients with advanced dementia locally. Training of doctors, nurses and other members of the healthcare teams are vital to the promulgation of CHF. There is an urgent need to enhance the present wards in public hospitals with a more elderlyfriendly environment. RCHEs staff training and ratio will be important factors of whether CHF can be smoothly practiced in the community of Hong Kong. Without a well-prepared receiving end, patients on CHF will be soon put on enteral tubes. The Social Welfare Department can play a role in to encourage RCHE in practicing EOL care and CHF. More palliative care training should be given to primary doctors who look after older people with advanced dementia (37). 


\section{Way forward}

In the 2015 Quality of Death Index by The Economist, Hong Kong ranks 22nd in the world (Singapore ranks 12th and Taiwan ranks 6th) (38). This index evaluates 80 countries using 20 quantitative and qualitative indicators across five categories: the palliative and healthcare environment, human resources, the affordability of care, the quality of care and the level of community engagement. There is a need for further development and expansion of EOL program for older people with advanced dementia in Hong Kong, in particular for those living in RCHEs. Hospital Authority has to work with the Fire Services Department to establish guideline for avoiding resuscitation amongst terminal patients who have opted not for resuscitation in advance directive or in other form of ACP. At the time of writing this article, the Hong Kong SAR Government is exploring the realisation of enduring power of attorney for health care decision, allowing mentally incapacitated older people to express their wishes through a chosen advocate (39). A successful EOL program for residents in RCHEs with advanced dementia or other irreversible chronic diseases can be a win-win situation. For the elderly, they could have a choice of a "good death"; and for hospitals, scarce resources would not be wasted on futile treatments. We need a "paradigm shift" in the end stage care of advanced dementia elderly. Hopefully, with our collective efforts, the dream of making dying in place and "good death" a reality for our older people with advanced dementia, can finally come true.

\section{Acknowledgements}

None.

\section{Footnote}

Conflicts of Interest: The authors have no conflicts of interest to declare.

\section{References}

1. Census and Statistics Department. Hong Kong Population Projections 2012-2041. Available online: http://www. statistics.gov.hk/pub/B1120015052012XXXXB0100.pdf

2. Hoffer LJ. Tube feeding in advanced dementia: the metabolic perspective. BMJ 2006;333:1214-5.

3. Mitchell SL, Teno JM, Kiely DK, et al. The clinical course of advanced dementia. N Engl J Med 2009;361:1529-38.

4. Luk JK, Chan WK, Ng WC, et al. Mortality and health services utilisation among older people with advanced cognitive impairment living in residential care homes. Hong Kong Med J 2013;19:518-24.

5. Mitchell SL, Kiely DK, Hamel MB, et al. Estimating prognosis for nursing home residents with advanced dementia. JAMA 2004;291:2734-40.

6. Marsh GW, Prochoda KP, Pritchett E, et al. Predicting hospice appropriateness for patients with dementia of the Alzheimer's type. Appl Nurs Res 2000;13:187-96.

7. Smith R. A good death: An important aim for health services and for us all. BMJ 2000;320:129-30.

8. Bosek MS, Lowry E, Lindeman DA, et al. Promoting a good death for persons with dementia in nursing facilities: family caregivers' perspectives. JONAS Healthc Law Ethics Regul 2003;5:34-41.

9. Luk JK, Kwok T, Woo J. Geriatric screening in acute care wards--a novel method of providing care to elderly patients. Hong Kong Med J 1999;5:34-8.

10. Chan WC, Tse HS, Chan TH. What is good death: Bridging the gap between research and intervention. In: Chan CL, Chow AY. editors. Death, Dying and Bereavement: A Hong Kong Chinese Experience. Hong Kong: Hong Kong University Press, 2006.

11. Luk JK, Liu A, Ng WC, et al. End-of-life care: towards a more dignified dying process in residential care homes for the elderly. Hong Kong Med J 2010;16:235-6.

12. Chan KS. Peaceful Death in Nursing Home - A Family Perspective. HKSPM Newsletter 2006:3.

13. Luk JK, Liu A, Ng WC, et al. End-of-life care in Hong Kong. Asian J Gerontol Geriatr 2011;6:103-6.

14. Lam PT, Madocks I. Dying in place-palliative care in nursing home-an Australian perspective and its relevance to Hong Kong. Hong Kong J Gerontol 1998;12:49-53.

15. Registration of a Death. The Immigration Department of the Hong Kong Special Administrative Region (HKSAR). Available online: http://www.immd.gov.hk/eng/about-us/ welcome.html

16. Application for a Permit for Removal of Dead Body from Hong Kong. The Immigration Department of the Hong Kong Special Administrative Region (HKSAR). Available online: http://www.immd.gov.hk/eng/services/birth-death/ Apply_for_a_permit_to_remove_a_dead_body_from_ Hong_Kong.html

17. CAP 504 Coroners Ordinance. Available online: http:// www.hklii.org/eng/hk/legis/ord/504/

18. Luk JK, Chiu PK, Chu LW. Factors affecting 
institutionalization in older Chinese patients after rehabilitation from acute medical problems. Arch Gerontol Geriatr 2009;49:e110-4.

19. Luk JK, Pau MM, Chan FH, et al. Outreach geriatric private nursing home service in Hong Kong Central and Western cluster. J Hong Kong Geriatr Soc 2002;11:5-10

20. Luk JK, Chu LW, Chan FH, et al. A study of the knowledge and preferences in Chinese elderly concerning advance directive. Hospital Authority Convention 2007.

21. Chu LW, Luk JK, Hui E, et al. Advance directive and end-of-life care preferences among Chinese nursing home residents in Hong Kong. J Am Med Dir Assoc 2011;12:143-52.

22. Chu WW, Leung AC, Lam C, et al. An evaluation of a shared care program in end-of-life care service in a subvented nursing home in Hong Kong. Hospital Authority Convention 2004.

23. Hui E, Ma HM, Tang WH, et al. A new model for endof-life care in nursing homes. J Am Med Dir Assoc 2014;15:287-9.

24. Ho AH, Luk JK, Chan FH, et al. Dignified Palliative Long-Term Care: An Interpretive Systemic Framework of End-of-Life Integrated Care Pathway for Terminally Ill Chinese Older Adults. Am J Hosp Palliat Care 2016;33:439-47.

25. The Gold Standards Framework. Available online: http:// www.goldstandardsframework.org.uk/

26. Luk JK, Chan TC, Chan WK, et al. End of life program in residential care homes reduces unnecessary hospital admissions and fosters 'good death' in last phase of life. Hospital Authority Convention 2015.

27. Luk JK, Chan TC, Mok WW, et al. End-of-life clinical plan in a geriatric step-down hospital. Asian J Gerontol Geriatr 2016;11:42-7.

28. Kuo S, Rhodes RL, Mitchell SL, et al. Natural history of feeding-tube use in nursing home residents with advanced dementia. J Am Med Dir Assoc 2009;10:264-70.

29. Teno JM, Mitchell SL, Kuo SK, et al. Decision-making and outcomes of feeding tube insertion: a five-state study. J
Am Geriatr Soc 2011;59:881-6.

30. Odom SR, Barone JE, Docimo S, et al. Emergency department visits by demented patients with malfunctioning feeding tubes. Surg Endosc 2003;17:651-3.

31. Mitchell SL, Tetroe JM. Survival after percutaneous endoscopic gastrostomy placement in older persons. J Gerontol A Biol Sci Med Sci 2000;55:M735-9.

32. American Geriatrics Society Ethics Committee and Clinical Practice and Models of Care Committee.

American Geriatrics Society feeding tubes in advanced dementia position statement. J Am Geriatr Soc 2014;62:1590-3.

33. Hanson LC, Ersek M, Gilliam R, et al. Oral feeding options for people with dementia: a systematic review. J Am Geriatr Soc 2011;59:463-72.

34. Australian and New Zealand Society for Geriatric Medicine. Position Statement 12: Dysphagia and Aspiration in Older People. 2010. Available online: http://www.anzsgm.org/documents/ PS12DYSPHAGIA2010cleanfinal.pdf

35. HA Guidelines on Life-Sustaining Treatment in the Terminally Ill. Hospital Authority 2015. Available online: http://www.ha.org.hk/haho/ho/psrm/HA_Guidelines_on_ Life_sustaining_treatement_en_2015.pdf

36. Luk JK, Chan FH, Hui E, et al. The feeding paradox in advanced dementia: a local perspective. Hong Kong Med J 2017;23:306-10.

37. Hong TC, Lam TP, Chao DV. Barriers for primary care physicians in providing palliative care service in Hong Kong - Qualitative study. Hong Kong Practitioner 2010;32:3-9.

38. The 2015 Quality of Death Index. Available online: https://www.eiuperspectives.economist.com/sites/default/ files/2015\%20EIU\%20Quality\%20of\%20Death\%20 Index \%20Oct\%2029\%20FINAL.pdf

39. The Law Reform Commission of Hong Kong Report. Enduring powers of attorney: personal care. Available online: http://www.hkreform.gov.hk/en/docs/repa2_e.pdf
Cite this article as: Luk JK, Chan FH. End-of-life care for advanced dementia patients in residential care home-a Hong Kong perspective. Ann Palliat Med 2018;7(3):359-364. doi: 10.21037/apm.2017.08.13 